\title{
Pendampingan Gerakan Reading Corner di SDN Inpres Samili 2 untuk Menumbuhkan Minat dan Budaya Literasi
}

\author{
Husnul Khatimah*, Nunung Fatimah, Surya Ningsih \\ STKIP Taman Siswa Bima, Bima, Indonesia \\ *Coresponding Author : husnul.khatimahh21@gmail.com \\ Dikirim: 16-08-2021 ; Diterima: 28-08-2021
}

\begin{abstract}
Abstrak: Perkembangan zaman yang semakin pesat membuat kegiatan membaca menjadi sangat memprihatinkan. Seperti masalah yang terjadi di SDN Inpres Samili 2 yaitu banyak siswa yang belum mempunyai kesadaran akan pentingnya membaca, tidak adanya perpustakaan serta kurangnya buku-buku sehingga siswa jarang sekali membaca di sekolah. Siswa hanya membaca buku teks pelajaran saat pembelajaran berlangsung. Sehingga kegiatan literasi menjadi hal yang tabu. Maka dari itu butuh perhatian khusus supaya dapat menumbuhkan budaya literasi di sekolah tersebut. Kegiatan pengabdian kepada masyarakat ini bertujuan untuk menumbuhkan budaya literasi siswa SDN Inpres Samili 2 melalui pendampingan pembuatan pojok baca "reading corner", pembiasaan membaca 15 menit sebelum pembelajaran berlangsung, menciptakan lingkungan yang kaya teks sehingga siswa terbiasa dengan membaca. Adapun tahapan pelaksanaan kegiatan pengabdian ini adalah sebagai berikut: (1) Tahap observasi lapangan, (2) Tahap sosialisasi kegiatan, (3) Tahap pendampingan. Hasil dan laporan kegiatan pengabdian ini akan diterbitkan pada media massa serta publikasi pada jurnal lokal. Kegiatan pengabdian pada masyarakat berupa pendampingan dalam pembuatan reading corner ini bertujuan untuk memberikan pengetahuan dalam meningkatkan minat dan budaya literasi di sekolah SDN Inpres Samili 2 yang berada di Desa Samili Kecamatan Woha Kabupaten Bima. Hal tersebut menunjukan bahwa keterampilan membaca Indonesia masih sangat rendah. Minat baca di SDN Inpres Samili 2 masih sangat rendah. Fakta tersebut didapatkan berdasarkan hasil obeservasi awal. Peningkatan budaya literasi dapat di mulai dari sekolahsekolah melalui buku-buku di perpustakaan. Untuk mendukung budaya literasi, maka sekolah harus memiliki sarana dan prasana yang memadai khususnya pengadaan buku di perpustakaan. Permasalahan yang ada di SDN Inpres Samili 2, tidak adanya perpustakaan serta kurangnya buku-buku sehingga siswa jarang sekali membaca di sekolah. Siswa hanya membaca buku teks pelajaran saat pembelajaran berlangsung. Sehingga kegiatan literasi menjadi hal yang tabu. Maka dari itu butuh perhatian khusus supaya dapat menumbuhkan budaya literasi di sekolah tersebut. Kegiatan pengabdian kepada masyarakat ini bertujuan untuk menumbuhkan budaya literasi siswa SDN Inpres Samili 2 melalui pengadaan pojok baca "reading corner", pembiasaan membaca 15 menit sebelum pembelajaran berlangsung, menciptakan lingkungan yang kaya teks, serta menata kelas yang kaya teks sehingga siswa terbiasa dengan membaca.
\end{abstract}

Kata Kunci: Budaya Literasi; Membaca; Reading Corner

Abstract: The development of an increasingly rapid era makes reading activities very worrying. Like the problems that occurred at SDN Inpres Samili 2, there were many students who did not have an awareness of the importance of reading, the absence of a library and the lack of books so that students rarely read at school. Students only read textbooks during learning. So that literacy activities are taboo. Therefore, special attention is needed in order to foster a culture of literacy in the school. This community service activity aims to foster a literacy culture for the students of SDN Inpres Samili 2 through assistance in making a reading corner "reading corner", the habit of reading 15 minutes before learning takes place, creating a text-rich environment so that students are familiar with reading. The stages of implementing this service activity are as follows: (1) Field observation stage, (2) Activity socialization stage,

@ 2021 JagoMipa (https://bimaberilmu.com/jurnal/index.php/jagomipa) 
(3) Assistance stage. The results and reports of this service activity will be published in the mass media and publications in local journals. This community service activity in the form of assistance in making reading corners aims to provide knowledge in increasing literacy interest and culture at the SDN Inpres Samili 2 school located in Samili Village, Woha District, Bima Regency. This shows that Indonesian reading skills are still very low. Interest in reading at SDN Inpres Samili 2 is still very low. These facts were obtained based on the results of initial observations. Improving literacy culture can be started from schools through books in the library. To support a literacy culture, schools must have adequate facilities and infrastructure, especially the procurement of books in the library. The problems that exist at SDN Inpres Samili 2 are the absence of a library and the lack of books so that students rarely read at school. Students only read textbooks during learning. So that literacy activities are taboo. Therefore, special attention is needed in order to foster a culture of literacy in the school. This community service activity aims to foster a literacy culture for SDN Inpres Samili 2 students through the provision of a "reading corner" reading corner, the habit of reading 15 minutes before learning takes place, creating a text-rich environment, and arranging text-rich classes so that students are accustomed to reading. Articles in the Bima Abdi: Jurnal Pengabdian Masyarakat are written on A4 paper size with $4 \mathrm{~cm}$ left margin, $2.5 \mathrm{~cm}$ right, $3 \mathrm{~cm}$ top, and $3 \mathrm{~cm}$ bottom. Write a brief and concise abstract in Indonesian that contains an explanation of the research objectives, methods used, findings, and conclusions. The number of words in the abstract is around 150 - 250 words. Abstract is written in Times New Roman font size 11. Abstract does not use or contain special characters, symbols or mathematical formulas. Abstracts must be clear, descriptive and provide a complete but concise picture of the problem under study. The abstract must contain the background of the problem, the urgency of the study, the objectives, methods and a brief summary of the research results, and end with a brief conclusion. Abstracts must be written in Indonesian and accompanied by an English version thereafter. It should be accurate, no evaluative, readable, and concise, followed by up to 5 keywords, separated by semicolons. Unlike pre-Google guidelines for maximum exposure of your work through your best search engine placement, it is highly recommended that keywords explicitly appear repeatedly in the Title and Abstract.

Keywords: Literacy Culture; Read; Reading Corner

\section{PENDAHULUAN}

Dalam Undang-Undang Nomor 20 Tahun 2003 tentang Sistem Pendidikan Nasional pasal 4 ayat 5 menyatakan bahwa "prinsip penyelenggaraan pendidikan adalah dengan mengembangkan budaya membaca, menulis dan berhitung bagi segenap warga masyarakat". budaya membaca di Indonesia masih sangat rendah, ini berarti kemampuan literasi masih rendah. Hal ini ditunjukan dengan kurangnya minat masyarakat dalam membaca baik pelajar, pekerja maupun bukan pekerja. Membaca itu sangat penting dilakukan, hal ini sesuai dengan pendapat Faradina (2017) bahwa membaca merupakan salah satu upaya yang sangat penting dalam proses pembelajaran.

Dengan membaca kita dapat menemukan informasi baru, pengetahuan baru serta berita-berita baru. Sebagai jembatan ilmu pengetahuan, membaca memiliki dampak yang luar biasa apabila diterapkan dalam kehidupan sehari-hari. Mereka yang gemar membaca akan mendapatkan informasi, ilmu pengetahuan dan teknologi, hiburan dan lain-lain. Dengan membaca berarti kita menerjemahkan, menginterpretasikan tandatanda atau lambing-lambang dalam bahasa yang dipahami oleh pembaca. Menurut Sutarno (2006) bahwa rendahnya minat baca masyarakat Indonesia salah satunya dipengaruhi oleh minimnya fasilitas-fasilitas pendukung, seperti tidak adanya 
perpustakaan di sekolah-sekolah. Kemampuan literasi sangat penting dikembangkan. Hal ini sejalan dengan Hasan (Kharizmi, 2015) bahwa kemampuan literasi memiliki peran penting dalam kehidupan seseorang untuk kesuksesan akademiknya. Kemampuan literasi inilah yang menjadi senjata utama bagi generasi bangsa Indonesia dan harus diajarkan usia dini.

Berdasarkan hasil observasi awal yang dilakukan di SDN Inpres Samili 2 yang berada di Desa Samili Kecamatan Woha Kabupaten Bima bahwa minat baca siswa masih sangat rendah.. Hal ini dikarenakan terbatasnya saran dan prasarana membaca, seperti ketersediaan perpustakaan dan buku-buku bacaan yang bervariasi sehingga penerapan literasi belum dapat dilakukan dengan optimal. Selain itu juga guru masih mengandalkan ketersediaan buku paket saja untuk kegiatan belajar di kelas, padahal ketersedian buku-buku bacaan penunjang yang menarik dan bermutu akan sangat memotivasi siswa dalam memperluas pengetahuannya. Situasi pembelajaran yang kurang memotivasi siswa untuk mempelajari buku-buku tertentu di luar buku-buku paket. Pembelajaran di kelas lebih sering masih berpusat pada guru atau sekedar mentransfer ilmu dimana siswa hanya dijajali oleh informasi/ pengetahuan dari guru dan jarang diajak berdiskusi atau diberi permasalahan tentang materi yang dibahas untuk diselesaikan bersama sehingga siswa termotivasi untuk mencari informasi dari sumber lain dan tidak terlatih untuk menambah pengetahuan melalui membaca. Sehingga perlu diadakannya inovasi baru untuk meningkatkan budaya literasi membaca di SDN Inpres Samili 2 yaitu dengan melakukan pendampingan pembuatan pojok baca "reading corner" serta membiasakan 15 menit membaca sebelum pembelajaran berlangsung

\section{METODE PELAKSANAAN KEGIATAN}

Dalam pelaksanaan Program Kemitraan Kepada Masyarakat (PKM) ini menggunakan metode dengan tahapan sebagai berikut:

\section{Tahap Observasi}

Observasi merupakan langkah awal dalam memastikan apa yang dihadapi oleh siswa, terutama dalam bidang membaca dan menulis, sehingga pada tahapan ini, Tim melaksanakan observasi di SDN Inpres Samili 2 sekaligus melihat kondisi sekolah serta menjalin komunikasi dengan Bapak Kepala Sekolah. Dengan demikian TIM dapat memetakan permasalahan yang dihadapi oleh mitra dalam Program Kemitraan Kepada Masyarakat (PKM).

\section{Tahap Penyusunan Proposal}

Berdasarkan hasil observasi TIM di SDN Inpres Samili 2 sehingga Tim dapat menyusun proposal berdasarkan permasalahan yang ada di sekolah mitra yaitu berkaitan dengan rendahnya minat baca dan tidak tersedianya perpustakaan sekolah, sekaligus akan memberikan solusi terhadap berbagai permasalahan yang dihadapi oleh mitra dengan membangun pojok baca.

\section{Tahap Sosialisasi}

Pada tahap sosialisasi kegiatan, Tim bersama Bapak Kepala Sekolah melaksanakan sosialisasi kegiatan kepada guru dengan menjelaskan tentang rencana, maksud dan tujuan kegiatan PKM kepada calon peserta kegiatan yaitu kegiatan pendapingan pembuatan reading corner dalam menumbuhkan minat dan budaya 
literasi, meski berorientasi pada siswa namun guru juga perlu mendapatkan gambaran dalam menumbuhkan minat baca siswa pada SDN Inpres Samili 2.

\section{Tahap Pendampingan}

Pada tahap ini, tim pelaksana pengabdian melakukan pendampingan bagi seluruh guru yang ada di SDN Inpres Samili 2, hal ini dilakukan dalam rangka memberikan pemahaman agar dalam pengadaan reading corner guna meningkatkan minat dan budaya literasi perlu memperhatikan desain dan gambar serta penyediaan buku-buku yang sesuai dengan hobi siswa pada masing-masing kelas, sehingga siswa tidak merasa jenuh dalam membaca sebab mereka belajar sambil bermain.

\section{Tahap Penyusunan Laporan Akhir}

Penyusunan laporan akhir ini dilakukan berdasarkan hasil pelaksanaan program kemitraan kepada masyarakat (PKM) di SDN Inpres Samili 2 tentang membangun pojok baca (Reading Corner) sebagai bahan untuk pertanggungjawaban tim terhadap kegiatan pengabdian yang dilaksanakan pada sekolah dan lembaga STKIP Taman Siswa Bima.

\section{IMPLEMENTASI KEGIATAN DAN PEMBAHASAN}

Program Kemitraan Kepada Masyarakat (PKM) ini merupakan salah satu bentuk kepedulian lembaga STKIP Taman Siswa Bima terhadap rendahnya minat baca di Kabupaten Bima Khususnya di SDN Inpres Samili 2. Dengan memberikan pengetahuan dan pendampingan dalam pengadaan pojok baca agar dapat meningkatkan minat baca dan budaya literasi bagi siswa SDN Inpres Samili 2, di samping itu, kegiatan ini juga merupakan bentuk realisasi pengabdian kepada masyarakat sebagai salah satu fungsi Tri Darma Perguruan Tinggi. Melalui kegiatan pendampingan ini telah banyak memberikan peningkatan kesadaran dan pengetahuan akan pentingnya meningkatkan minat baca dan budaya literasi.

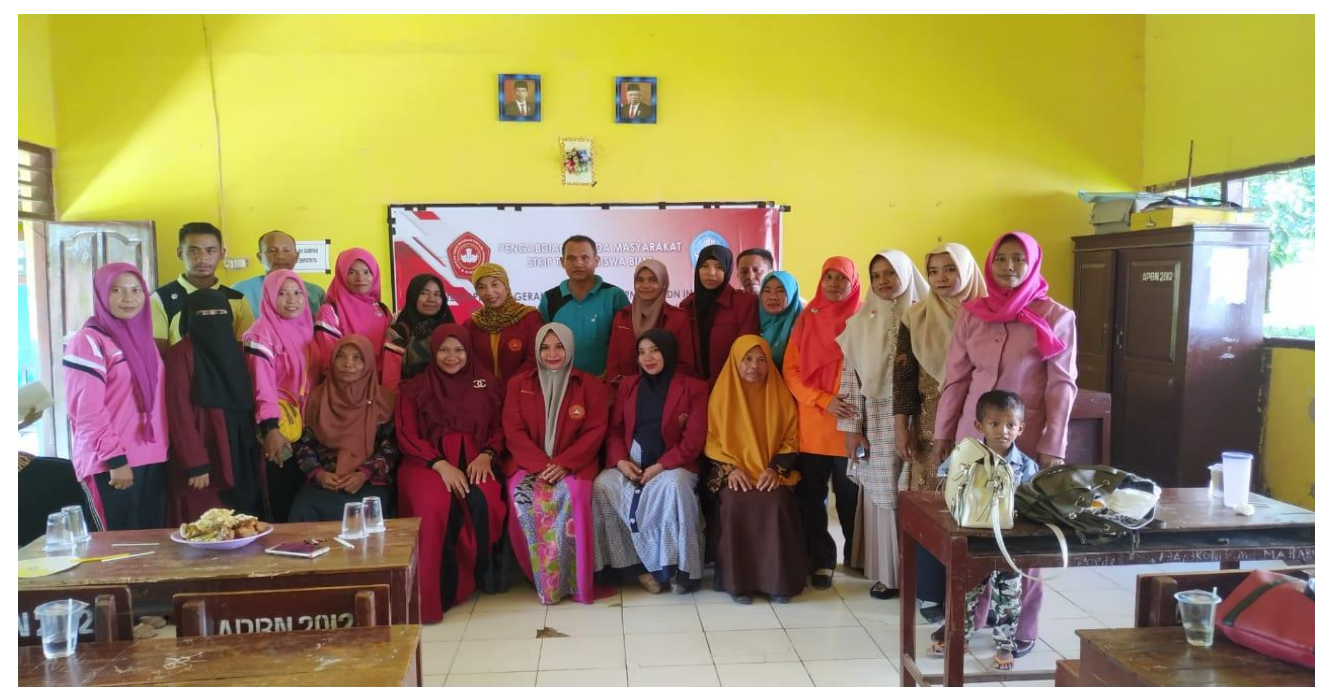

Gambar 1. Dokumentasi bersama guru SDN Inpres Samili 2 


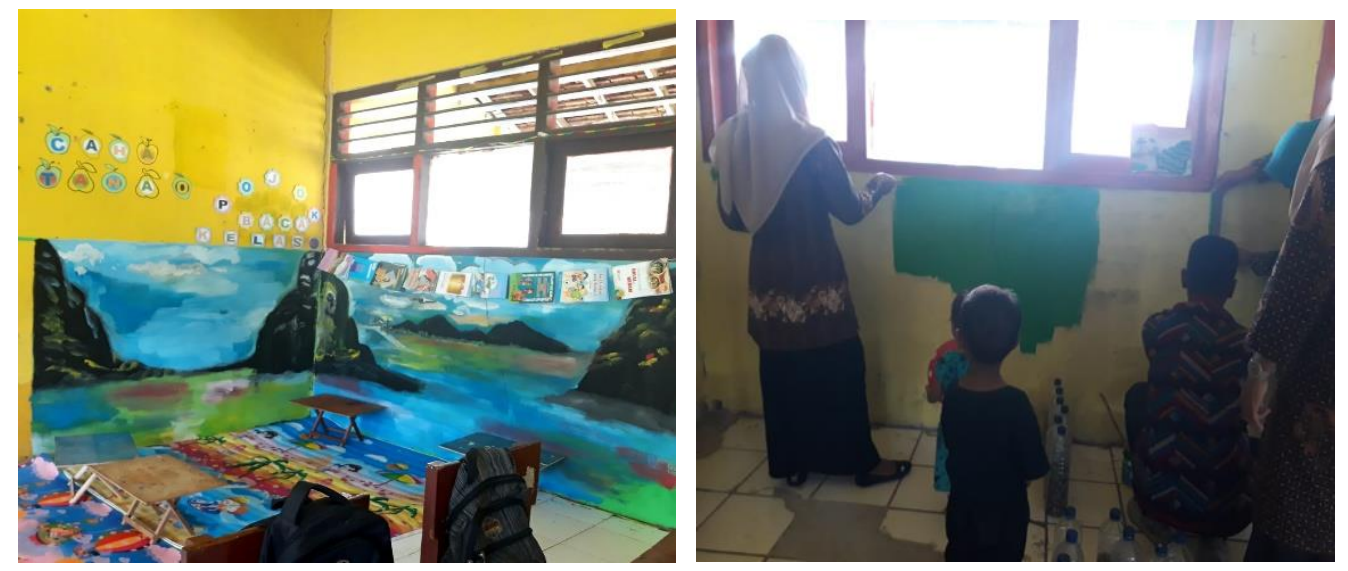

Gambar 2. Proses Pembuatan Pojok Baca

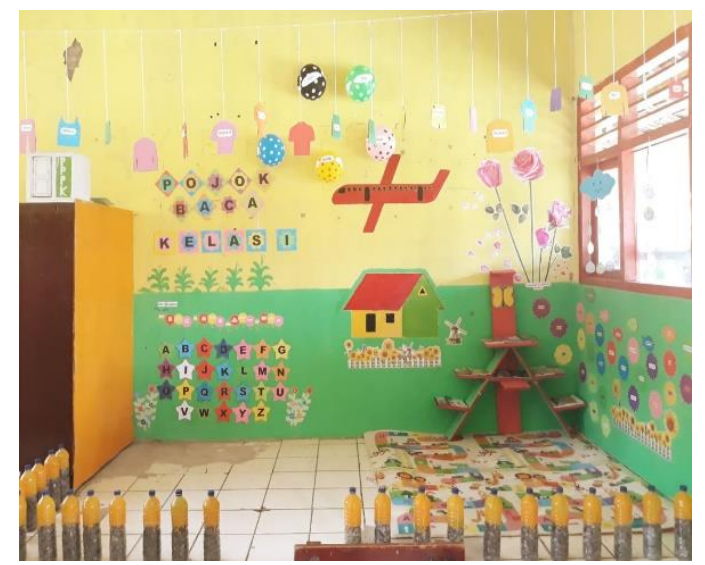

Gambar 3. Tampak Depan Pojok Baca Di SDN Inpres Samili 2

Dengan adanya kegiatan pendampingan ini, telah menghasilkan pojok baca di kelas rendah SDN Inpres Samili 2 sebagai penunjang dari perpustakaan sekolah. Selain peserta didik membaca, meminjam dan menjelajah sumber ilmu dari perpustakaan sekolah, peserta didik juga bisa memanfaatkan pojok baca di kelas mereka masingmasing. Buku yang terdapat pada rak buku pojok baca adalah buku koleksi peserta didik sendiri, sehingga mereka dapat bertukar pinjam dengan teman-temannya.

\section{KESIMPULAN}

Berdasarkan pelaksanaan pengabdian kepada masyarakat melalui program kemitraan kepada masyarakat (PKM) dengan kesimpulan sebagai berikut:

1. Dengan hadirnya pojok baca menjadi peran penting dalam menumbuhkan minat membaca siswa di Sekolah, hal ini dapat terwujud karena di dalam pojok baca terdapat banyak buku mulai dari buku pelajaran sampai buku non pelajaran, pojok baca juga dihias semenarik dan senyaman mungkin untuk membuat siswa tertarik dan merasa betah berada di dalam pojok baca tersebut.

2. Melalui program pojok baca menjadi lebih baik dan berpengaruh terhadap perilaku sosial peserta didik diantaranya siswa; memiliki sifat cakap dalam berbicara, lebih rajin dan hormat kepada orang yang lebih tua 


\section{DAFTAR PUSTAKA}

Faradina, N. (2017). Pengaruh Program Gerakan Literasi Sekolah terhadap Minat Baca Siswa di SD Islam Terpadu Muhammadiyah An-Najah Jatinom Klaten.Hanata Widya,6(8), 60-69

Kharizmi, Muhammad. 2015. Kesulitan Siswa Sekolah DAsar dalam Meningkatkan Kemapuan Literasi: Jupendas, Vo;.02, No.02, 2355-3650.

Sutarno, NS. (2006). Manajemen Perpustakaan: suatu pendekatan praktik. Jakarta: Sagung Seto 